\title{
Urethral plate in tubularized incised plate urethroplasty: how wide is enough?
}

\author{
Bin Zhang, Shuangsui Ruan, Yunli Bi \\ Department of Pediatric Urology, Children's Hospital of Fudan University, Shanghai, China \\ Contributions: (I) Conception and design: B Zhang, Y Bi; (II) Administrative support: Y Bi; (III) Provision of study materials or patients: B Zhang, S \\ Ruan, Y Bi; (IV) Collection and assembly of data: B Zhang, Y Bi; (V) Data analysis and interpretation: B Zhang, Y Bi; (VI) Manuscript writing: All \\ authors; (VII) Final approval of manuscript: All authors. \\ Correspondence to: Bin Zhang; Yunli Bi. Department of Pediatric Urology, Children's Hospital of Fudan University, 399 Wanyuan Road, Shanghai \\ 201102, China. Email: ningmengganying@163.com; biyunli@yahoo.com.
}

Background: Previous reports found that a preincision urethral plate (UP) width $<8 \mathrm{~mm}$ increased the
occurrence of urethroplasty complications (UCs) in tubularized incised plate (TIP) hypospadias repair.
However, is the classification of the UP width based on an $8 \mathrm{~mm}$ cut-off value to predict the outcome of TIP
urethroplasty objective enough or universally applicable? The purpose of our study was to assess the effect of
the UP width on the outcomes of TIP hypospadias repair in the Eastern population we served. Methods: We retrospectively reviewed the records of patients who underwent TIP hypospadias repair by the same surgeon between August 2013 and December 2019 in our hospital. Data were collected, including demographics, intrinsic parameters of the penis, surgical parameters and subsequent surgical outcomes. The data were analyzed and the cut-off value of the UP width was calculated using a receiving-operator curve.

Results: Primary TIP urethroplasty was carried out in 116 patients with a mean age of 35.89 \pm 29.40 months. The meatal location was distal in 49 patients, midshaft in 56 patients and proximal in 11 patients. The mean glans width was $12.28 \pm 1.36 \mathrm{~mm}$, the mean UP width was $5.74 \pm 1.37 \mathrm{~mm}$, the mean neourethral length was $1.96 \pm 1.32 \mathrm{~cm}$, and the mean operation duration was $87.52 \pm 11.47 \mathrm{~min}$. During a median follow-up of 42 (range: 6 to 80 ) months, UCs developed in 12 patients, and the UP width was significantly related to the occurrence of $\mathrm{UCs}(\mathrm{P}=0.014)$. According to the $6 \mathrm{~mm}$ cut-off value of the UP width by the receiver operating characteristic curve, patients were divided into two groups. Group A (UP width $\geq 6 \mathrm{~mm}$ ) included 69 patients, and Group B (UP width $<6 \mathrm{~mm}$ ), 47 patients. UCs occurred in 3 patients in Group A vs. 9 patients in Group B, $\mathrm{P}=0.010$.

Conclusions: UP width is a potential risk factor for UCs after TIP hypospadias repair. Using this technique with an UP width $\geq 6 \mathrm{~mm}$ is sufficient to result in a good outcome of hypospadias repair.

Keywords: Tubularized incised plate (TIP); hypospadias; urethral plate (UP); urethroplasty complications (UCs)

Submitted Sep 09, 2020. Accepted for publication Dec 07, 2020.

doi: $10.21037 / \mathrm{tau}-20-1243$

View this article at: http://dx.doi.org/10.21037/tau-20-1243

\section{Introduction}

The goal of hypospadias repair should be to achieve a normal-looking penis with good function and to reduce the occurrence of urethroplasty complications (UCs) postoperatively. Since Snodgrass described tubularized incised plate (TIP) urethroplasty in 1994 (1), this technique has gradually become the most common method for hypospadias repair with preservation of the urethral plate (UP).

As the name implies, the outcomes of TIP urethroplasty depend on the condition of the UP. In this century, two reports found that a preincision UP width $<8 \mathrm{~mm}$ increased the occurrence of UCs in TIP hypospadias repair $(2,3)$. However, is the classification of the UP width based on 


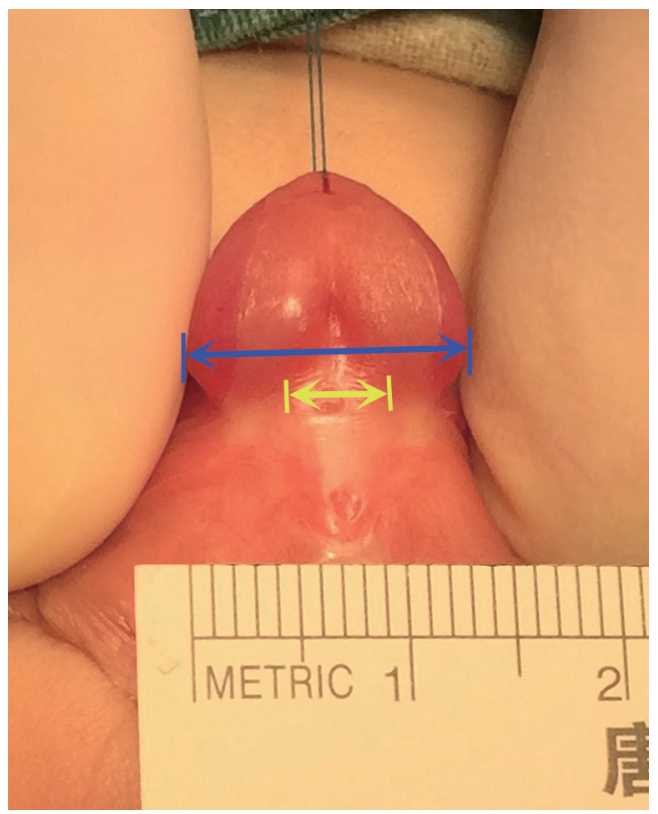

Figure 1 Measurements of glans width (blue line) and urethral plate width (yellow line).

an $8 \mathrm{~mm}$ cut-off value to predict the outcome of TIP urethroplasty objective enough or universally applicable? On the basis of predecessors, targeting the Eastern population we served, we reviewed our experience in TIP hypospadias repair and evaluated the effect of the UP width on the outcome of this technique.

We present the following article in accordance with the STROBE reporting checklist (available at http://dx.doi. org/10.21037/tau-20-1243).

\section{Methods}

Patients who underwent TIP hypospadias repair by the same surgeon between August 2013 and December 2019 in the Urology Department, Children's Hospital of Fudan University, Shanghai, China, were retrospectively analyzed. The study was conducted in accordance with the Declaration of Helsinki (as revised in 2013) and approved by the Ethics Board of the Children's Hospital of Fudan University \{No. [2019]208\}. Due to the retrospective nature of the study, individual consent was waived. Patients with proximal hypospadias found to have a ventral curvature $>30^{\circ}$ after degloving and dartos dissection were excluded from the study. Patients who had been operated on for hypospadias repair before and patients who had received exogenous testosterone before were also excluded.

Data were collected, including demographics, intrinsic parameters of the penis, surgical parameters and subsequent surgical outcomes. Intrinsic parameters of the penis included the meatal location after cutting the membrane urethra, glans and UP width. Measurement was made at the widest point of the glans and UP using a flexible sterile ruler, as described by Holland (2). When measuring, the UP should be stretched horizontally to be flat (Figure 1). Surgical parameters included the neourethral length and operation duration.

All patients underwent the TIP procedure after measurement of various intrinsic parameters of the penis. After degloving and dartos dissection, if a mild ventral curvature (between $10^{\circ}$ and $30^{\circ}$ ) remained, dorsal midline plication was performed to correct it. The bilateral edges of the UP were incised along the marked line from the true meatus to the distal margin, dissecting deeply down to the corpora cavernosa. The two wings of the glans were carefully expanded to at least the 3 and 9 o'clock positions of the penis, even the 2 and 10 o'clock positions in some cases, as described by Snodgrass (4).

With the help of an assistant, the UP was incised along the midline from within the meatus to the top edge, also reaching deeply down to the corpora cavernosa. Urethroplasty was carried out in two subepithelial layers using 7-0 polydioxanone with running sutures. The neourethra was covered with a single dartos flap harvested from dorsal preputial skin. Glansplasty was performed with two interrupted subepithelial sutures with 6-0 polyglactin approximating the glans wings without tension. A silicone Foley catheter (6-10 Fr) was used for urinary drainage in all patients, and then the surgical area was bandaged with gauze.

All patients were discharged with a urinary catheter on the third postoperative day after removal of the gauze and examination of the wound. The urinary catheter was removed between the 10th and 12 th postoperative days at the outpatient department.

All postoperative patients were followed-up regularly at 6 weeks, 6 months, 1 year and annually. The UCs included any of the following during follow-up: fistula, glans dehiscence, diverticula, meatal stenosis, and urethral stricture. Glans dehiscence was defined as complete separation of the glans wings resulting in a coronal meatus. Meatal stenosis or urethral stricture was diagnosed by both obstructive voiding symptoms and calibration $<8 \mathrm{Fr}$ in infants or $<10 \mathrm{Fr}$ in older boys. Cystoscopy was performed 


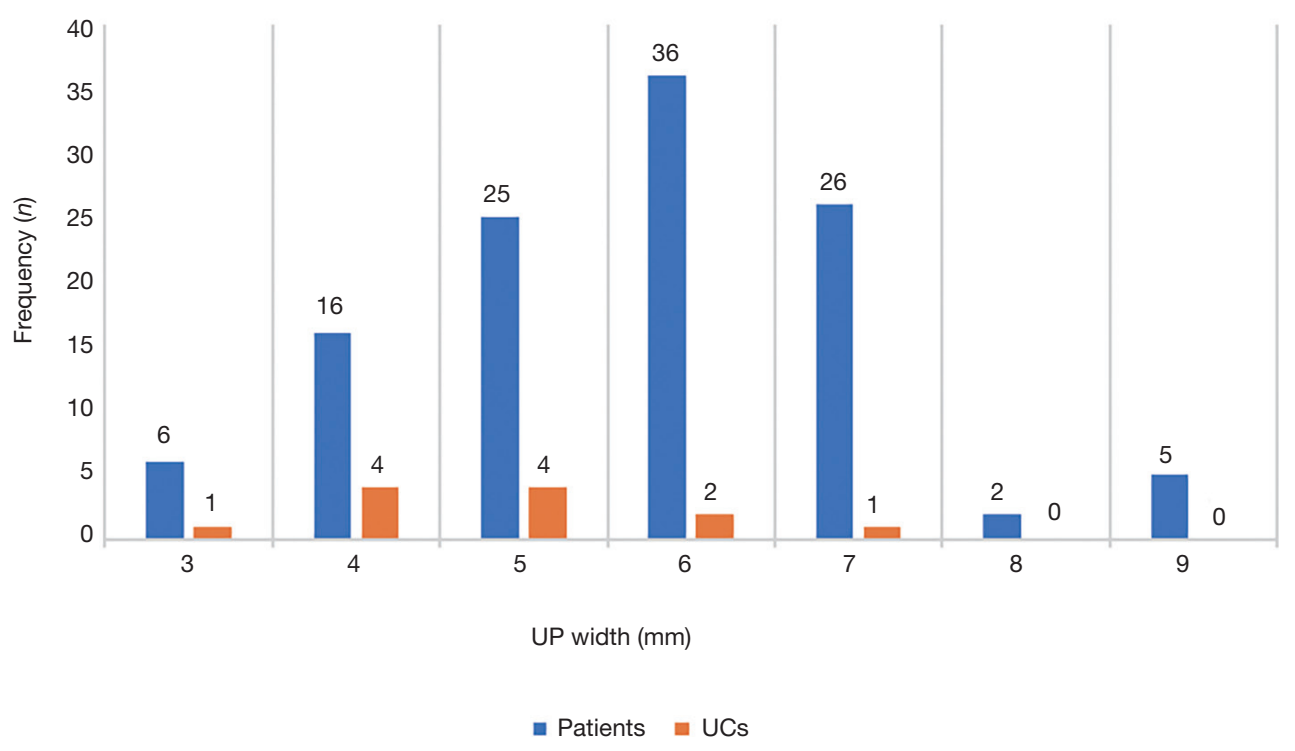

Figure 2 Frequency of patients and urethroplasty complications (UCs) for different urethral plate (UP) widths.

for further confirmation when managing meatal stenosis or urethral stricture.

Another experienced pediatric urologist made the diagnosis of UCs, and all the complications were managed by the original surgeon.

\section{Statistical analysis}

All analyses were carried out using SPSS version 20.0 (IBM Corp., Armonk, NY, USA). Univariate analysis with a Chisquared or $t$ test was used to assess possible risk factors for UCs, and the difference between two groups was distinguished by the cut-off value of the UP width. The cut-off value of the UP width was further analyzed by ROC analysis. All tests were two-sided, and $\mathrm{P}$ values $<0.05$ were considered significant.

\section{Results}

During the study period, the single surgeon (Dr. Zhang) performed TIP hypospadias repair for 134 individuals, in which, 18 patients were excluded because of exclusion criteria. A total of 116 patients were enrolled in this study at a mean age of $35.89 \pm 29.40$ months. The meatal location was distal in $49(42.24 \%)$ patients, midshaft in $56(48.28 \%)$ patients and proximal in $11(9.48 \%)$ patients. The mean glans width was $12.28 \pm 1.36 \mathrm{~mm}$, the mean UP width was $5.74 \pm 1.37 \mathrm{~mm}$, the mean neourethral length was $1.96 \pm 1.32 \mathrm{~cm}$, and the mean operation duration was $87.52 \pm 11.47 \mathrm{~min}$. The UP width was $\geq 8 \mathrm{~mm}$ in only $7 / 116(6.03 \%)$ patients.

During a median follow-up of 42 (range 6 to 80 ) months, UCs developed in 12 patients $(10.34 \%)$ and consisted of fistula in $8(6.90 \%)$, glans dehiscence in $3(2.59 \%)$ and meatal stenosis in $1(0.86 \%)$. No diverticula or urethral stricture was observed in any case.

A univariate analysis of the possible risk factors for UCs is shown in Table 1. Age at operation $(\mathrm{P}=0.633)$, meatal location $(\mathrm{P}=0.759)$, glans width $(\mathrm{P}=0.409)$, neourethral length $(\mathrm{P}=0.675)$ and operation duration $(\mathrm{P}=0.110)$ had no impact on the occurrence of UCs. However, the UP width was significantly related to the occurrence of $\mathrm{UCs}(\mathrm{P}=0.014)$.

Figure 2 shows the frequency of patients and UCs for different UP widths. ROC analysis was used to determine the value of the UP width, with area under the curves of 0.719. According to the Youden index, the cut-off value was $5.5 \mathrm{~mm}$. Due to the precise unit when measuring, $6 \mathrm{~mm}$ cut-off value of the UP width was finally determined. Accordingly, patients were divided into two groups: Group A (UP width $\geq 6 \mathrm{~mm}$ ) and Group B (UP width $<6 \mathrm{~mm}$ ) (Table 2). Group A included 69/116 (59.48\%) patients, and Group B included 47/116 (40.52\%) patients. Between the two groups, the differences were not statistically significant in age at operation $(\mathrm{P}=0.153)$, meatal location $(\mathrm{P}=0.075)$, glans width $(\mathrm{P}=0.126)$, neourethral length $(\mathrm{P}=0.957)$ and operation duration $(\mathrm{P}=0.111)$. Therefore, the surgical 
Table 1 Univariate analysis of the possible risk factors for urethroplasty complications

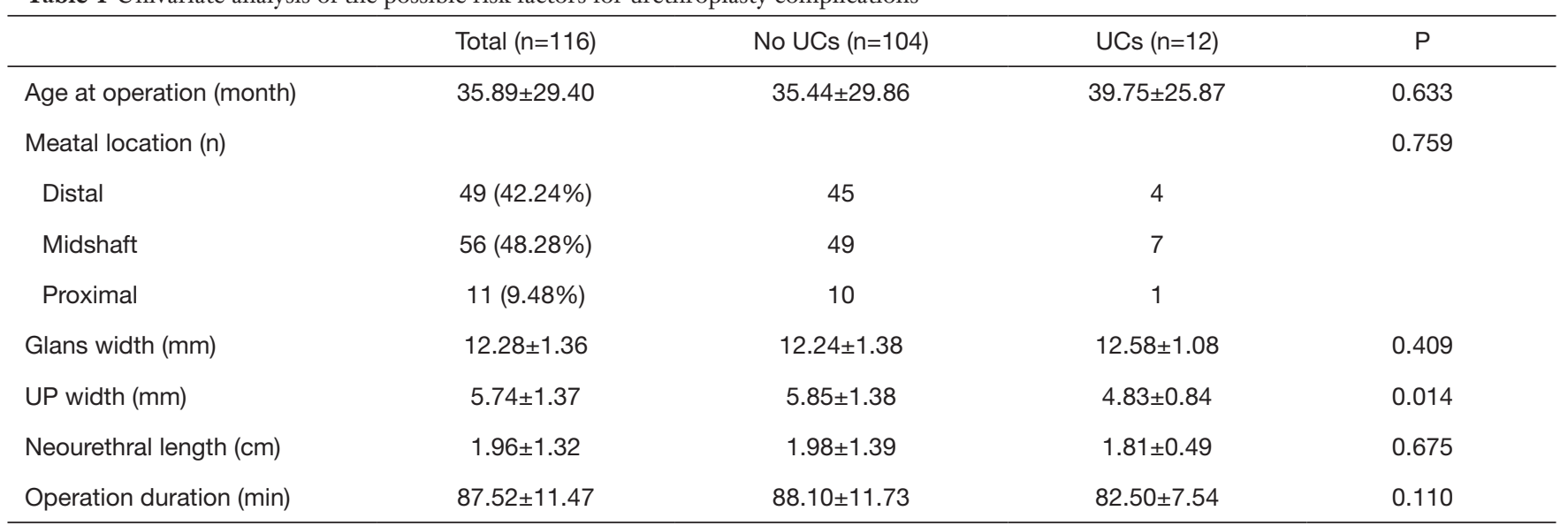

UCs, urethroplasty complications.

Table 2 Parameters and urethroplasty complications correlated to urethral plate width

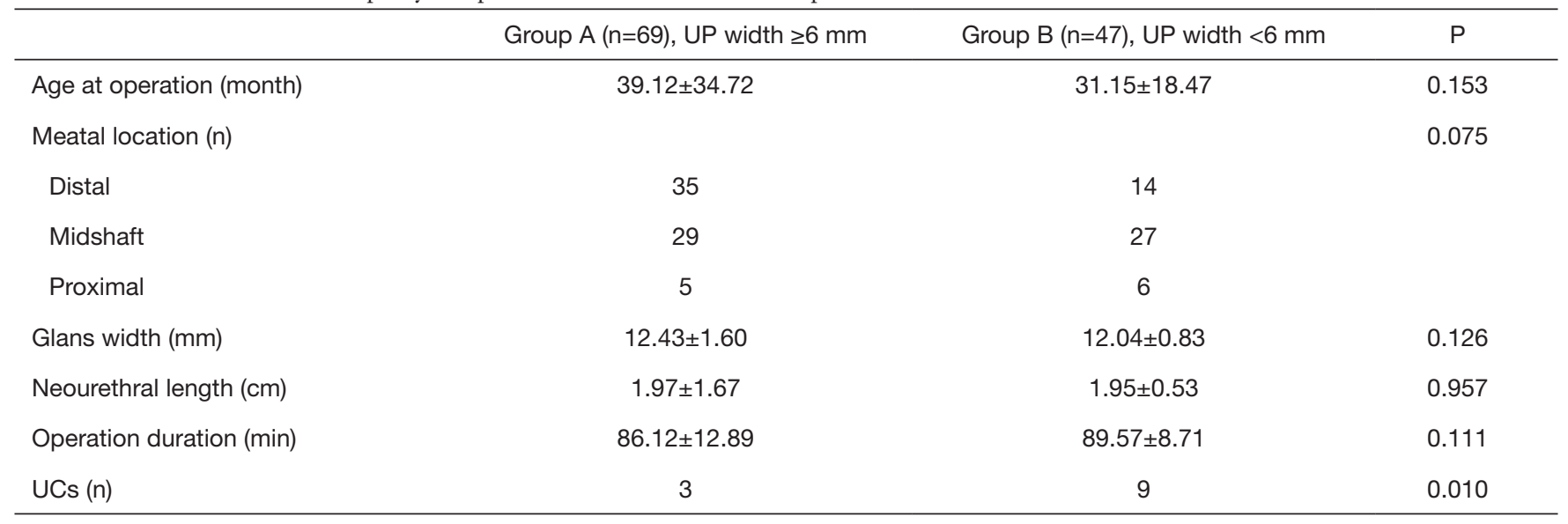

UCs, urethroplasty complications; UP, urethral plate.

outcomes of Group A and Group B were comparable. UCs occurred in 3/69 (4.35\%) patients in Group A vs. 9/47 (21.3\%) patients in Group B, $\mathrm{P}=0.010$.

\section{Discussion}

Hypospadias is always a concern because of its high incidence, occurring in 1 in 200 to 1 in 300 live births $(5,6)$. Surgical repair is the only way to treat hypospadias and is recommended for functional, psychological, and cosmetic reasons (7). The aim of hypospadias repair is the creation of a straight penis with a slit-like meatus at the tip of the glans (8). Because of its relatively simple surgical concepts, low UC rates, and good cosmetic outcome, the
TIP procedure, which was described by Snodgrass in 1994, has gained worldwide acceptance for distal and midshaft hypospadias repair $(9,10)$. This technique of urethroplasty is recommended even for more severe hypospadias and reoperation cases (11).

The essence of the TIP procedure lies in the fact that urethroplasty does not require any other urethral substitutes, such as inner prepuce flap, oral mucosal graft, scrotal flap, etc., but only the original urethral tissue. Therefore, compared with other surgical methods, the TIP procedure depends more on the development of the UP. In recent years, many studies have reported on the UP characteristics in the success of TIP hypospadias repair. Holland et al. first reported that a pre-relaxing incision UP 
width $<8 \mathrm{~mm}$ predicted an increased risk for fistulas after distal TIP urethroplasty, which occurred in all patients with this plate diameter (2). Subsequently, Sarhan et al. also found that the UP characteristics had a nonsignificant impact on the complication rate except for the plate width and recommended that an adequate UP width $(8 \mathrm{~mm}$ or greater) was essential for successful TIP repair (3). Other studies reported that the UP characteristics have no effect on the outcome of TIP hypospadias repair. Because of the low complication rate after TIP urethroplasty regardless of the urethral plate configuration or width, the TIP procedure promoted by Nguyen et al. is potentially applicable in all cases of primary distal hypospadias (12). In a series of 224 primary TIP repairs reported by Bush and Snodgrass (13), $86 \%$ of the UP widths were $<8 \mathrm{~mm}$, remarkably higher than the $37.5 \%$ reported by Holland (2) and $48.8 \%$ reported by Sarhan (3). However, they found that the UP width before incision did not increase the occurrence of UCs. Rather, they confirmed that a glans width $<14 \mathrm{~mm}$ increases the likelihood of complications.

Penile dimensions vary among different ethnicities, and penis size is generally slightly smaller in Chinese patients than in Western patients (14-17). Ru et al. reported in their study of 442 Chinese boys who underwent TIP hypospadias repair that the mean age was 2.8 years, the mean glans width was $13.9 \mathrm{~mm}$, and the mean UP width was $5.3 \mathrm{~mm}$ (18). From our data in this study, the mean age was 35.89 months, the mean glans width was $12.28 \mathrm{~mm}$, and the mean UP width was $5.74 \mathrm{~mm}$, similar to what Ru reported. Current guidelines consider the optimal age for hypospadias repair to be somewhere between 6 and 18 months, depending on the severity and the need for multiple procedures (19). Does this mean that TIP repair is not suitable for Eastern boys with hypospadias, or is it necessary to wait until boys are old enough such that their penis size is sufficient for surgery? Our data must be retrospectively analyzed to evaluate the potential risk factors in relation to UCs after TIP hypospadias repair.

One major survey involving a review of English literature from Medline/PubMed over 13 years reported that the UC rate of the TIP procedure ranged from 0 to $50 \%$ with a median rate of $7.3 \%$ (20). Published results for more than 2,000 patients who had undergone TIP urethroplasty for primary hypospadias repair have been summarized, and the mean UC rate after TIP repair was 10.8\% (21-23). In our study, the overall UC rate was $10.34 \%$, almost identical to that reported in the literature above. This similarity means that TIP hypospadias repair is still suitable for
Eastern boys, even though the penis size is not sufficient. We also found that the occurrence of UCs after TIP repair was not correlated with age, meatal location, glans width, neourethral length or operation duration but only with UP width. Sarhan et al. also analyzed the effect of the suturing technique on the UC rate (3). Although they proved that the suture technique had no influence on the outcome of TIP urethroplasty, we unified the suture technique used for all patients to avoid this potential risk factor.

In our study, the mean UP width was $5.74 \mathrm{~mm}$, which was similar to the $6 \mathrm{~mm}$ reported by Bush (13) and $5.3 \mathrm{~mm}$ reported by $\mathrm{Ru}(18)$ but remarkably smaller than the $8 \mathrm{~mm}$ reported by Sarhan (3). Meanwhile, the UP width was $\geq 8 \mathrm{~mm}$ only in $7 / 116(6.03 \%)$ patients. Obviously, classification of the UP width based on an $8 \mathrm{~mm}$ cut-off value to predict the outcome of TIP urethroplasty, first described by Holland (2), is not universally applicable. Nevertheless, we tried to use a $6 \mathrm{~mm}$ cut-off value based on the frequency of patients and UCs for different UP widths. In fact, our results indicated that UCs after TIP urethroplasty occurred more often in patients with UP widths of less than $6 \mathrm{~mm}(\mathrm{P}=0.010)$. Bush et al. emphasized that the UP width did not require consideration as long as the TIP incision was sufficiently deep (13). However, Eassa et al. completed an experimental animal study and declared that the average gain in UP width after the midline relaxing incision was only $2 \mathrm{~mm}$ (24). Accordingly, we may need to consider the narrow UP and use different surgical methods to improve the success rate of surgery and reduce postoperative complications. Kolon et al. (25) and Asanuma et al. (23) both recommended dorsal inlay graft urethroplasty (DIGU) to effectively reduce the risk of UC in hypospadias repair with small glans and narrow UP, which make tubularization difficult. However, some other surgeons preferred to use the onlay island flap (OIF) technique in these cases $(26,27)$.

According to the literature, different from our measurement of UP, there were also several useful methods of UP quality assessment in TIP urethroplasty. Ru et al. reported the width proportion of the urethral plate to the glans (U/G) was an appropriate evaluation for urethral plate quality in TIP repair (18). In addition, Abbas et al. recommended a Plate Objective Scoring Tool (POST) score for the objective assessment of UP characteristics (28). The advantage of this method was that it had a high degree of inter and intraobserver reliability.

Our study has limitations. While the UP width was mainly studied, we did not entirely assess factors such as 
the type of hypospadias because of the small sample size. We hope that after expanding the sample size, making a stratified study may be more convincing. Meanwhile, it is a retrospective study. The parameters measurement during the surgery was completed by the same surgeon which resulted in observer bias. In the future, we need a multicenter prospective study to verify our results.

\section{Conclusions}

Based on our findings, the UP width is a potential risk factor for UCs after TIP hypospadias repair. Using this technique with an UP width $\geq 6 \mathrm{~mm}$ is sufficient to result in a good outcome of hypospadias repair. Furthermore, when the UP width $<6 \mathrm{~mm}$, other choices, such as the DIGU or OIF technique, may be better to improve the results of hypospadias repair.

\section{Acknowledgments}

We thank the parents of all the patients included in this study. We also thank all members of the Department of Urology at the Children's Hospital of Fudan University.

Funding: None.

\section{Footnote}

Reporting Checklist: The authors have completed the STROBE reporting checklist. Available at http://dx.doi. org/10.21037/tau-20-1243

Data Sharing Statement: available at http://dx.doi. org/10.21037/tau-20-1243

Conflicts of Interest: All authors have completed the ICMJE uniform disclosure form (available at http://dx.doi. org/10.21037/tau-20-1243). The authors have no conflicts of interest to declare.

Ethical Statement: The authors are accountable for all aspects of the work in ensuring that questions related to the accuracy or integrity of any part of the work are appropriately investigated and resolved. The study was conducted in accordance with the Declaration of Helsinki (as revised in 2013) and approved by the Ethics Board of the Children's Hospital of Fudan University \{No. [2019]208\}. Due to the retrospective nature of the study, individual consent was waived.
Open Access Statement: This is an Open Access article distributed in accordance with the Creative Commons Attribution-NonCommercial-NoDerivs 4.0 International License (CC BY-NC-ND 4.0), which permits the noncommercial replication and distribution of the article with the strict proviso that no changes or edits are made and the original work is properly cited (including links to both the formal publication through the relevant DOI and the license). See: https://creativecommons.org/licenses/by-nc-nd/4.0/.

\section{References}

1. Snodgrass W. Tubularized, incised plate urethroplasty for distal hypospadias. J Urol 1994;151:464-5.

2. Holland AJ, Smith GH. Effect of the depth and width of the urethral plate on tubularized incised plate urethroplasty. J Urol 2000;164:489-91.

3. Sarhan O, Saad M, Helmy T, et al. Effect of suturing technique and urethral plate characteristics on complication rate following hypospadias repair: a prospective randomized study. J Urol 2009;182:682-5.

4. Bush NC, Villanueva C, Snodgrass W. Glans size is an independent risk factor for urethroplasty complications after hypospadias repair. J Pediatr Urol 2015;11:355.e1-5.

5. Paulozzi LJ, Erickson JD, Jackson RJ. Hypospadias trends in two US surveillance systems. Pediatrics 1997;100:831-4.

6. Springer A, van den Heijkant M, Baumann S. Worldwide prevalence of hypospadias. J Pediatr Urol 2016; 12:152.e1-7.

7. Paulozzi LJ. International trends in rates of hypospadias and cryptorchidism. Environ Health Perspect 1999;107:297-302.

8. Aboutaleb H. Role of the urethral plate characteristics in the success of tubularized incised plate urethroplasty. Indian J Plast Surg 2014;47:227-31.

9. Bhattacharya S. A modified tubularized incised plate urethroplasty technique and a revised hypospadias algorithm. Indian J Plast Surg 2010;43:21-7.

10. Braga LH, Lorenzo JA, Salle PJ. Tubularized incised plate urethroplasty. Indian J Urol 2008;24:219-25.

11. Eliçevik M, Tireli G, Demirali O, et al. Tubularized incised plate urethroplasty for hypospadias reoperations in 100 patients. Int Urol Nephrol 2007;39:823-7.

12. Nguyen MT, Snodgrass W. Effect of urethral plate characteristics on tubularized incised plate urethroplasty. J Urol 2004;171:1260-2.

13. Bush NC, Snodgrass W. Pre-incision urethral plate width does not impact short-term tubularized incised plate 
urethroplasty outcomes. J Pediatr Urol 2017;13:e1-6.

14. Wessells H, Lue TF, McAninch JW. Penile length in the flaccid and erect states: guidelines for penile augmentation. J Urol 1996;156:995-7.

15. Ponchietti R, Mondaini N, Bonafè M, et al. Penile length and circumference: a study on 3300 young Italian males. Eur Urol 2001;39:183-6.

16. Khan S, Somani B, Lam W, et al. Establishing a reference range for penile length in Caucasian British men: a prospective study of 609 men. BJU Int 2012;109:740-4.

17. Chen XB, Li RX, Yang HN, et al. A comprehensive, prospective study of penile dimensions in Chinese men of multiple ethnicities. Int J Impot Res 2014;26:172-6.

18. Ru W, Shen J, Tang D, et al. Width proportion of the urethral plate to the glans can serve as an appraisal index of the urethral plate in hypospadias repair. Int J Urol 2018;25:649-53.

19. Riedmiller H, Androulakakis P, Beurton D, et al; European Association of Urology. EAU guidelines on paediatric urology. Eur Urol 2001;40:589-99.

20. Braga LHP, Lorenzo AJ, Pippisalle JL. Tubularized incised plate urethroplasty for distal hypospadias: A literature review. Indian J Urol 2008;24:219-25.

21. Elbakry A. Tubularized incised plate urethroplasty for distal hypospadias: is regular dialation is necessary for

Cite this article as: Zhang B, Ruan S, Bi Y. Urethral plate in tubularized incised plate urethroplasty: how wide is enough? Transl Androl Urol 2021;10(2):703-709. doi: 10.21037/tau-201243 success? BJU Int 1999;84:683-8.

22. Singh RB, Pavithran NM. Lessons learnt from Snodgrass TIP Urethroplasty: a study of 75 cases. Pediatr Surg Int 2004;20:204-6.

23. Asanuma H, Satoh H, Shishido S. Dorsal inlay graft urethroplasty for primary hypospadiac repair: Int J Urol 2007;14:43-7.

24. Eassa W, He X, El-Sherbiny M. How much does the midline incision add to urethral diameter after tubularized incised plate urethroplasty? An experimental animal study. J Urol 2011;186:1625-9.

25. Kolon TF, Gonzales ET. The dorsal inlay graft for hypospadias repair. J Urol 2000;163:1941-3.

26. Shimotakahara A, Nakazawa N, Wada A, et al. Tubularized incised plate urethroplasty with dorsal inlay graft prevents meatal/neourethral stenosis: a single surgeon's experience. J Pediatr Surg 2011;46:2370-2.

27. Mohajerzadeh L, Mirshemirani A, Rouzrokh M, et al. Evaluation of Onlay Island Flap Technique in Shallow Urethral Plate Hypospadiasis. Iran J Pediatr 2016;26:e660.

28. Abbas TO, Vallasciani S, Elawad A, et al. Plate Objective Scoring Tool (POST); An objective methodology for the assessment of urethral plate in distal hypospadias. J Pediatr Urol 2020;16:675-82. 